\title{
l. Entre la autoridad eclesiástica y el liderazgo local: los curas párrocos de la diócesis de Tucumán durante el primer peronismo ${ }^{1}$
}

\author{
Lucía Santos Lepera²
}

\begin{abstract}
Resumen
La historiografía sobre la relación de la Iglesia católica y el peronismo en Argentina se enfocó en los vínculos entre las altas esferas de la institución eclesiástica y el Estado desde una perspectiva político-institucional. Tributario de los enfoques socioculturales desarrollados en los últimos años en torno a la Iglesia y el catolicismo, el presente estudio busca ampliar y complejizar el abordaje de este tema. Con ese fin, analiza el derrotero de los curas párrocos de Famaillá y Monteros -pueblos ubicados en el centro del cordón agroindustrial azucarero de la provincia de Tucumán- entre 1946 y 1952. Teniendo en cuenta los cambios introducidos por la emergencia del peronismo en la dinámica política y social de las comunidades azucareras, el estudio se pregunta por el rol de los curas párrocos, sus formas de intervención en las poblaciones locales y las implicancias de sus opciones políticas en el ámbito parroquial. De ese modo, indaga en las tensiones que recorrieron ambas trayectorias, atravesadas por la disyuntiva entre la obediencia a la jerarquía eclesiástica y la afirmación de un liderazgo local.
\end{abstract}

Palabras clave: curas párrocos; diócesis de Tucumán; peronismo; agroindustria azucarera.

\footnotetext{
1 Una versión preliminar de este trabajo fue presentada en las XIV Jornadas Interescuelas/Departamentos de Historia, Mendoza, 2 al 5 de octubre 2013, Facultad de Filosofía y Letras, Universidad Nacional de Cuyo. Agradezco los comentarios realizados en esa oportunidad por Liliana Da Orden y las pertinentes sugerencias de Ignacio Sánchez y Florencia Gutiérrez; como también las observaciones de los evaluadores anónimos de la revista.

2 Instituto Superior de Estudios Sociales-Universidad Nacional de Tucumán/Consejo Nacional de Investigaciones Científicas y Técnicas. Argentina. Correo electrónico: luciasantoslepera@gmail.com
} 
Between ecclesiastical authority and local leadership: parish priests of the Diocese of Tucumán during the first peronism

\begin{abstract}
The historiography on the relationship of the Catholic Church and Peronism in Argentina focused on the links between the upper echelons of the ecclesiastical institution and the state from a political and institutional perspective. Taking into account the new sociocultural perspectives that in recent years developed around the Church and Catholicism, the present study seeks to expand the approach to this issue. This article analyzes the itinerary of the parish priests of Famaillá and Monteros -villages located in the center of the sugar agro cordon of the province of Tucuman- between 1946 and 1952. Considering the changes introduced by the emergence of Peronism in the political and social dynamics of sugar communities, the study wonders about the role of parish priests, their forms of intervention in local populations and the implications of their political choices in parishes. In this way, we explore the tensions that toured both trajectories, crossed by the disjunction between the obedience to the ecclesiastical hierarchy and the assertion of a local leadership. Key words: parish priests; diocese of Tucumán; Peronism; sugar agroindustry.
\end{abstract}

Fecha de recepción de originales: 07/08/2014.

Fecha de aceptación para publicación: 03/09/2014.

\title{
Entre la autoridad eclesiástica y el liderazgo local: los curas párro- cos de la diócesis de Tucumán durante el primer peronismo
}

D entro del amplio espectro de estudios sobre la relación entre la Iglesia católica y el peronismo puede reconocerse el predominio de una perspectiva político-institucional, que priorizó los vínculos entre las altas esferas de la institución eclesiástica y el Estado. ${ }^{3}$ En los últimos años, nuevos abordajes incorporaron herramientas propias de la historia social y cultural en las investigaciones sobre la Iglesia católica contemporánea, que Ilamaron la atención sobre la necesidad de avanzar en la comprensión de la institución eclesiástica en su articulación con la sociedad. ${ }^{4}$ Siguiendo esa línea de indagación, el presente artículo centra la mirada en los curas párrocos, actores clave de la institución

\footnotetext{
3 Los libros de Caimari (1995); Zanatta (1996, 1999); Di Stefano y Zanatta (2000); Bianchi (2001) constituyen los estudios referentes sobre el tema. Sus investigaciones conformaron el cuerpo teórico-historiográfico central sobre esta problemática y abrieron camino a las reflexiones sobre la relación Iglesia-Estado desde una perspectiva histórica.

4 Para un balance historiográfico, véase Touris (2008); la introducción al libro de Lida y Mauro (2009); Lida y Mauro $(2009,2011$ a y 2011b).
} 
eclesiástica que, sin embargo, fueron casi inexplorados por la historiografía sobre el primer peronismo. De ese modo, nuestra investigación busca reducir la escala de análisis al ámbito parroquial con el fin de examinar la interacción, en un radio reducido, de los distintos actores políticos y eclesiásticos de la comunidad local. ${ }^{5}$

El objetivo del artículo es analizar el derrotero de los curas párrocos de Monteros y Famaillá, localidades ubicadas en el centro del cordón agroindustrial azucarero de la provincia de Tucumán. Se trata de dos trayectorias signadas por los contrastes, las cuales mostraron una marcada afinidad con el peronismo, en el primer caso, y un abierto rechazo a éste, en el segundo. La exploración de sendos itinerarios nos permite recuperar las múltiples dimensiones del rol de los sacerdotes y las implicancias de sus opciones políticas en el ámbito parroquial. En efecto, sus historias nos enclavan en la escala local, donde las tensiones se reprodujeron y dieron rienda suelta a pugnas entre fieles, obispo y autoridades de gobierno, que salieron a la luz en forma constante durante el período analizado.

La irrupción del peronismo tuvo un gran impacto en los pueblos azucareros de la provincia. Generó una intensa politización y complejizó la dinámica local a raíz del surgimiento de nuevos factores de poder, como por ejemplo, los sindicatos obreros de los ingenios. ${ }^{6}$ En el contexto de reconfiguración del tablero de poder local de las comunidades azucareras y del empoderamiento de nuevos actores sociales, nos preguntamos por el modo en que los curas párrocos fueron interpelados por éstos y condicionados en el desempeño de su ministerio pastoral. Se argumenta, en ese sentido, que a lo largo del período analizado se exacerbaron las tensiones propias de su rol bifronte, atravesado por la disyuntiva entre la obediencia a la jerarquía eclesiástica y la construcción de un liderazgo local.

5 En ese sentido, retomamos una fructífera línea de investigación desarrollada para el período tardocolonial y comienzos del siglo XIX que indagó en torno al papel y perfiles de los párrocos, su autonomía y condicionamientos, y los cambios en el ejercicio del ministerio parroquial, ver Ayrolo (2006); Barral (2007).

6 La emergencia del peronismo posibilitó el empoderamiento y la organización de los obreros azucareros a partir del surgimiento de la Federación Obrera Tucumana de la Industria Azucarera (FOTIA), quienes obtuvieron crecientes cuotas de poder en el ámbito político y social; véase Rubinstein (2006); Gutiérrez (2012). Sobre los cambios que introdujo el peronismo en la dinámica política y social de los pueblos azucareros, remitirse a Gutiérrez (2012a);.Lichtmajer (2013). 
Mapa de las parroquias de la diócesis de Tucumán (1955)

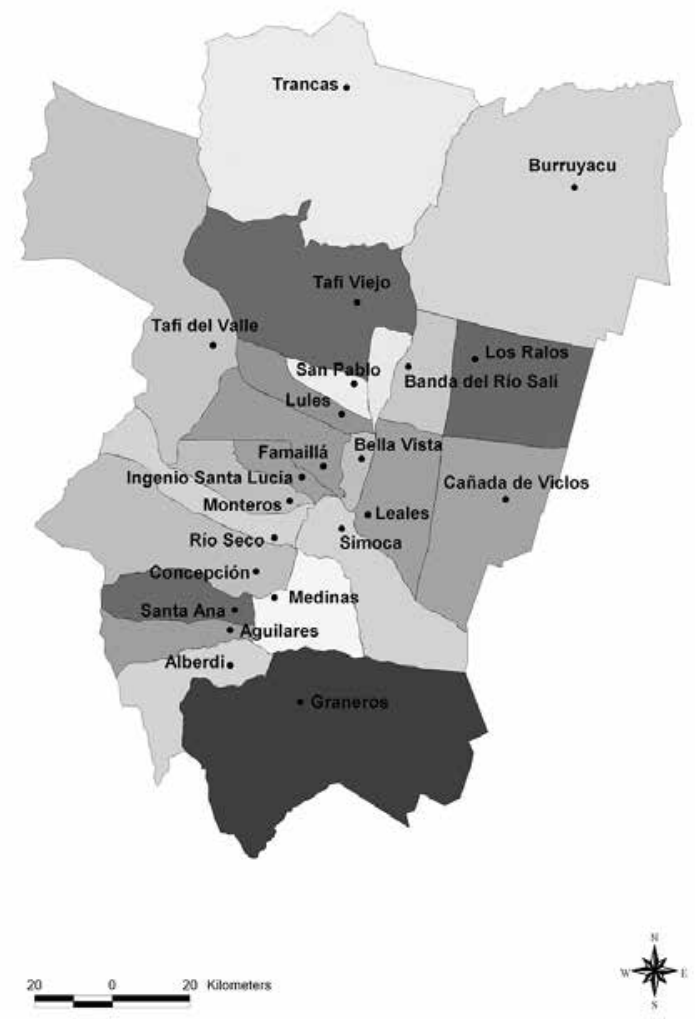

Fuente: Actas de fundaciones de parroquias. Archivo del Arzobispado de Tucumán y Archivo de la Diócesis de Concepción, Tucumán.

Nota: elaboración del mapa a cargo del Laboratorio de Cartografía Digital, Instituto Superior de Estudios Sociales, Universidad Nacional de Tucumán-Consejo Nacional de Investigaciones Científicas y Técnicas.

\section{Ecos de la disputa peronismo-antiperonismo: los conflictos locales en la parroquia de Famaillá}

El 25 de febrero de 1946, Ángel Diez y Menéndez asumió al frente de la parroquia de Famaillá, una de las jurisdicciones donde el nuevo movimiento político había suscitado mayor adhesión entre la población. ${ }^{7}$ Este religioso

7 La parroquia se emplazaba en el pueblo de Famaillá, capital del departamento homónimo, que hacia 1947 contaba con alrededor de 4.000 habitantes. Se ubicaba en el corazón del cordón agroindustrial azucarero, donde el laborismo triunfó con el $75,7 \%$ de los votos. Se caracterizaba por la presencia de una gran cantidad de población obrera (60\%) que trabajaba en los cinco establecimientos industriales azucareros con los que contaba el departamento. Dirección Nacional del Servicio Estadístico (1947). 
nació en Oviedo, España, en 1904. Llegó a la Argentina en 1926 y consiguió la incardinación en la diócesis de Tucumán en 1932, a partir de la cual ocupó distintos cargos. ${ }^{8}$ Fue vicario cooperador del barrio obrero de Villa Luján de San Miguel de Tucumán, vicario ecónomo de Graneros y encargado de la capilla del Ingenio San Pablo en el departamento Famaillá, última tarea que desempeñó antes de presidir la parroquia del distrito. ${ }^{9}$

Desde su llegada a Famaillá, Diez y Menéndez se convirtió en una figura resistida entre la feligresía. Asimismo, su animosidad y falta de colaboración con el gobierno durante los primeros años peronistas le generaron algunos problemas con la jerarquía eclesiástica tucumana. ${ }^{10}$ No obstante, fue en ocasión de la muerte de Eva Duarte de Perón (26 de julio de 1952) cuando estalló la hostilidad silenciosa de la población parroquial.

La noche en que se dio a conocer el deceso de la Primera Dama se congregó una multitud en la puerta de la iglesia local, con el propósito de rezar y pedir al cura párroco que oficiara una misa en sufragio del alma de la extinta. Pese a la creciente afluencia de fieles que se acercaron al templo, el sacerdote se negó a abrir las puertas de la parroquia hasta tanto no tuviera una orden directa de las autoridades eclesiásticas. La actitud del párroco contrastó con la del clero en general, que manifestó su buena predisposición a abrir las parroquias y acompañar el duelo popular, singularidad que definió a Famaillá como una excepción en un territorio provincial en el que abundaron expresiones contrapuestas. En ese contexto, la negativa de Diez y Menéndez de permitir el ingreso de los vecinos a la iglesia y los incidentes posteriores, generados por los empujones e insultos dirigidos al cura, persuadieron a un grupo de personas a trasladarse a la comisaría local para denunciar su actitud. Acto seguido, la jefatura de policía de Tucumán elevó las denuncias al Consejo Federal de Seguridad (dependiente del Ministerio del Interior), entidad que elaboró un Memorándum en el cual se culpó al cura por "desafecto al Superior Gobierno de

8 Carta de Diez y Menéndez a Agustín Barrere. 26 de enero de 1932. Legajo de Ángel Diez y Menéndez. Archivo del Arzobispado de Tucumán (AAT), San Miguel de Tucumán.

9 Hacia 1955, la diócesis de Tucumán contaba con 35 parroquias que se distribuían entre la capital (11) y los departamentos del interior de la provincia (24). Este entramado parroquial conformaba un conjunto heterogéneo que se había ido desarrollando desde fines del siglo XIX al calor del "despegue" de la agroindustria azucarera. Las parroquias se concentraron principalmente en el área del piedemonte tucumano, al sudoeste de la capital, donde predominaba la población dedicada a la elaboración de azúcar (ver mapa).

10 En 1949, Diez y Menéndez fue el único párroco que se rehusó a enviar la información solicitada desde el Ministerio de Relaciones Exteriores y Culto para la elaboración de la credencial eclesiástica. En una carta al obispo auxiliar, el cura expresó su oposición a la medida ya que obedecía a una "obra judío-masónica-comunista" del gobierno, cuyo fin principal era "tener fichados a todos los sacerdotes de la República" y de ese modo controlar la acción del clero. Finalmente, tras la insistencia del obispo Barrere, Diez y Menéndez envió las planillas con la información requerida para evitar ser señalado como opositor; escenario que le podía traer muchos problemas con su feligresía. Carta de Diez y Menéndez a Juan Carlos Aramburu. 26 de junio de 1949. Legajo Ángel Diez y Menéndez. AAT, San Miguel de Tucumán. 
la Nación". ${ }^{11}$ El informe -que reunía las denuncias-, una serie de artículos de la prensa en contra del párroco y los antecedentes recopilados por la policía, fueron enviados por el subsecretario de Culto al obispo auxiliar Juan Carlos Aramburu. En sus conclusiones solicitó el traslado de Diez y Menéndez, con el fin de llevar "la tranquilidad espiritual a la población católica" de esa localidad. ${ }^{12}$

Según se desprende de las denuncias del grupo de vecinos, la actitud del párroco frente a la muerte de Eva Perón fue el detonante que hizo estallar un malestar acumulado. ${ }^{13}$ Los incidentes ocurridos la noche del 26 de julio fueron el escenario en el que cristalizaron resentimientos previos y se liberaron las hostilidades en torno al cura y su ministerio parroquial. Desde su arribo al pueblo, distintos comportamientos le valieron la enemistad creciente de un sector de los fieles católicos, en especial sus diatribas públicas contra el gobierno. Resultaba frecuente para los concurrentes a la misa dominical escuchar a Diez y Menéndez criticar las reformas sociales impulsadas desde el Estado, arremeter contra la política impositiva oficial y lamentar la "inmoralidad" promovida desde las altas esferas del gobierno. Este último aspecto lo llevó a impartir insultos, a través de los altoparlantes de la iglesia, contra instituciones deportivas y sociales locales por organizar espectáculos cinematográficos y teatrales que no condecían con la moral católica pero que, sin embargo, contaban con el aval de las autoridades peronistas. Todas estas razones nutrían la lista de quejas de los vecinos, quienes se manifestaban cansados del "maltrato" que el cura dispensaba a la población y de su "actitud prepotente", la cual generaba un fuerte "divisionismo" entre los pobladores. ${ }^{14}$ Los vecinos se referían al cura párroco como alguien ajeno a la comunidad y con un sentido de la moralidad que entró en conflicto con el de aquellos. Tal diferencia se convirtió en uno de los problemas que definió la oposición al cura.

Como consecuencia de su cruzada en defensa de la moral del pueblo, días antes del estallido del conflicto, el párroco había decidido quitar su aval a

\footnotetext{
11 Memorándum del Ministerio del Interior producido por el Consejo Federal de Seguridad para información del Sr. Subsecretario del Ministerio del Interior Dr. A. Krislavin. Buenos Aires, 4 de agosto de 1952. Correspondencia Oficial con el Ministerio de Relaciones Exteriores y Culto. AAT, San Miguel de Tucumán (en adelante Memorándum).

12 El Memorándum fue remitido por Leonardo Benítez de Aldama al obispo auxiliar Juan Carlos Aramburu pidiendo que lo someta a consideración. Asimismo, le solicitó que informe a la Subsecretaría sobre las medidas oportunas que tomara, Correspondencia Oficial con el Ministerio de Relaciones Exteriores y Culto. 27 de agosto de 1952. AAT, San Miguel de Tucumán.

13 Las denuncias fueron remitidas por el jefe de Policía de Tucumán, coronel (R) Jorge Roberto Torres, al Sr. Presidente del Consejo Federal de Seguridad en julio de 1952. Correspondencia Oficial con el Ministerio de Relaciones Exteriores y Culto. AAT, San Miguel de Tucumán.
}

14 Carta de Rubén Leoncio Acosta al ministro del Interior Ángel Borlenghi, julio de 1952. Incluida en el Memorándum. Correspondencia Oficial con el Ministerio de Relaciones Exteriores y Culto. AAT, San Miguel de Tucumán. 
los festejos patronales de la Virgen del Carmen. ${ }^{15}$ Desde su perspectiva, las fiestas patronales de Famaillá ofrecían un caldo de cultivo para la realización de bailes y juegos populares que terminaban en excesos de alcohol y espectáculos inmorales. Dado que la arista festiva de la celebración patronal -como los reclamos de los agentes eclesiásticos por un mayor recato en los festejos- no eran privativos de ese período, la actitud del cura fue interpretada por los vecinos como una provocación a la comisión organizadora, presidida por Juan Isa. En efecto, este último era dirigente de la Sociedad de Obreros San José, entidad cuyos miembros adherían al peronismo y que, como veremos, fue acusada por el párroco en más de una oportunidad por su "tendencia radical e izquierdista" y por fomentar el "ambiente de inmoralidad" que reinaba en esa localidad. ${ }^{16}$ En julio de 1952, Isa se convirtió en uno de los vecinos que lideraron con mayor ímpetu la campaña de desprestigio hacia el religioso.

Las tensiones generadas en esa oportunidad reflejaron, por otro lado, una disputa más profunda entre redes asociativas en torno a la organización de las festividades religiosas. Cabe reparar en las directivas que emitió en 1950 el obispo tucumano respecto de las fiestas patronales, lo cual nos permite ponderar otros aspectos que subyacían a los entredichos entre el sacerdote de Famaillá y la comisión organizadora de los festejos religiosos. En efecto, Agustín Barrere envió una circular confidencial a los curas párrocos, estableciendo pautas para la conformación de comisiones protemplo y festejos patronales. El espíritu de la misiva era acotar la participación y reducir el protagonismo de los políticos peronistas en ellas. El prelado indicaba la necesidad de "retomar" la tradición por la cual los curas se vinculaban con "personas católicas prácticas de intachable reputación" y con "ascendiente entre los habitantes de la localidad" para integrar dichas comisiones. De ese modo, apuntaba a que los párrocos no incluyesen a "legisladores nacionales o provinciales, ni a autoridades de destacada actuación política" porque cerraban las puertas a la colaboración de personas que no adscribían "a la misma ideología política". ${ }^{17}$

15 El cura no autorizó a la comisión organizadora para celebrar la fecha un día no laborable. Las acusaciones fueron publicadas en el diario local La Censura, incluido en el Memorándum. Asimismo, la comisión organizadora publicó sus quejas en el diario La Gaceta del 5 de julio de 1952. Archivo del diario, San Miguel de Tucumán. El pedido de la comisión de realizar un día domingo las celebraciones buscaba incrementar la concurrencia de gente.

16 Carta de Ángel Diez y Menéndez a Juan Carlos Aramburu. 11 de septiembre de 1952. Legajo de Diez y Menéndez. AAT, San Miguel de Tucumán. En los años cuarenta, la Sociedad de Obreros San José constituía una institución tradicional en el pueblo que tenía a su cargo la promoción de la sociabilidad local, a partir de lo cual organizaba funciones de cine (la Sociedad fue propietaria de la primera sala de cine del pueblo), espectáculos teatrales, entre otros eventos. Dicha entidad había sido fundada en 1911 como una Asociación de Socorros Mutuos destinada a "promover el bienestar material y espiritual" de la clase obrera de Famaillá. Reglamento de la Sociedad Obreros de San José de Famaillá de 1911. Carpeta de Asociaciones Católicas. AAT, San Miguel de Tucumán.

17 Circular confidencial a los Sres. Párrocos sobre comisiones pro templo y de festejos patronales. 20 de diciembre de 1950. Carpeta con circulares al clero diocesano y regular. AAT, San Miguel de Tucumán. 
Por otro lado, las palabras del obispo expresaban un profundo rechazo a los cambios que introdujo la irrupción del peronismo en las relaciones de poder de las comunidades locales. Desde su asunción en 1930, Barrere había revelado una visión jerárquica y aristocrática de sus funciones, a partir de la cual se había acostumbrado a interactuar con los sectores altos de la sociedad y a interpelarlos con el fin de que intervinieran en las asociaciones católicas. ${ }^{18}$ En ese sentido, la "tradición" que el obispo llamaba a retomar era la de una vinculación entre la Iglesia y las elites locales, a las cuales temía ver excluidas de la sociabilidad católica parroquial. Por otro lado, sus directivas suponían también un reconocimiento de los conflictos de clase cristalizados durante esos años y que fueron particularmente tangibles en los pueblos azucareros, atravesados por un recrudecimiento de la confrontación entre los obreros organizados y los propietarios y administradores de las fábricas (Gutiérrez, 2012a). En suma, el comunicado de Barrere transmitía su temor frente a una dinámica parroquial que parecía transformarse, en la cual los curas redefinieron sus formas de intervención en las comunidades a partir de la interacción con nuevos actores sociales y políticos. Esto alimentó una complejidad que escapaba al control del obispo.

En el contexto de tales disyuntivas, la conducta de Diez y Menéndez se mostró en sintonía con las directivas obispales. El cura párroco desautorizó a la comisión organizadora de los festejos patronales, presidida por Juan Isa y formada, entre otros, por una diputada peronista por Famaillá. Promovió, en su lugar, la conformación de una comisión paralela compuesta por católicos notables del pueblo, con el fin de garantizar el recato en los festejos y la observancia de la moral. ${ }^{19}$ Con este gesto, Diez y Menéndez reclamaba el predominio del accionar asociativo en ese ámbito, frente a la influencia que buscaban ejercer la Sociedad de Obreros y figuras de la política local. De forma similar a los resquemores expresados en el comunicado del obispo, la resistencia del párroco a aceptar los nuevos términos y jerarquías de las relaciones de poder local quedó reflejada en su descargo frente a las acusaciones de los vecinos. ${ }^{20}$ Este testimonio expuso, con singular elocuencia, el complejo cuadro de tensiones locales desatadas al calor de la emergencia peronista.

Desde la perspectiva de Diez y Menéndez, el enfrentamiento con la

18 Sobre el perfil de la gestión de Agustín Barrere, véase Santos Lepera (2012a y 2012b).

19 Sobre las tensiones en torno a la organización del festejo patronal en Famaillá, consultar La Gaceta de los días 5 (p. 6), 16 (p. 7 ) y 17 (p. 7) de julio de 1952. Archivo del diario, San Miguel de Tucumán.

20 El obispo auxiliar Juan Carlos Aramburu envió el Memorándum a Diez y Menéndez y le solicitó su "versión” sobre lo ocurrido la noche del deceso de Eva Perón. Carta de Juan Carlos Aramburu a Diez y Menéndez. Septiembre de 1952. Legajo de Diez y Menéndez. AAT, San Miguel de Tucumán. 
Sociedad de Obreros San José era la razón última de los "ataques" que sufría y del ensañamiento del grupo de personas que lo denunció la noche del 26 de julio. ${ }^{21}$ Responsabilizó a sus dirigentes por los excesos cometidos en las fiestas patronales al dar "margen a situaciones dolorosas para la salud moral del pueblo y su unidad". Sin embargo, el párroco no solo había condenado a la Sociedad por esa razón, sino que también había prohibido a los católicos del pueblo asistir a la función de una compañía de ballet programada por esa institución y que, en sus palabras, "no era otra cosa que un conjunto pornográfico". ${ }^{22}$ En el intento de reafirmar su versión, el cura se apoyó en el testimonio de José Albornoz, un "católico respetable de Famaillá", quien abonó a sus argumentos al calificar a los dirigentes de la Sociedad como "obreros comunistas y anticlericales" que buscaban, en el fondo, perjudicar al párroco y a los vecinos decentes. ${ }^{23}$ El cuadro de inmoralidad se completaba con el dato, resaltado en la respuesta del cura y en el testimonio de Albornoz, de que el presidente de la entidad, Juan Isa, era hermano de la subdelegada censista local del Partido Peronista Femenino, señalada como la responsable de "episodios altamente inmorales que atacaban la honra y dignidad de las damas del pueblo".

De ese modo, la defensa del cura se centró en su rol de guardián de una moral local amenazada por el grupo de personas que lo había denunciado; en el alegato, éstas aparecían vinculadas a una asociación obrera anticlerical cuya dirigencia "inmoral y mentirosa" estaba ligada a la estructura peronista local. El discurso ético del párroco, teñido fuertemente por una moral de clase, señaló las conductas de los obreros y de una "mujer" peronista como amenazas a la "decencia" del pueblo, en especial a las "damas", término que comportaba hondos significados al ser contrapuesto al de las "mujeres" que hacían política. En su descargo afloró el rechazo a la consolidación de los nuevos poderes que habían surgido en la comunidad local tras la irrupción del peronismo y el carácter revulsivo que éste comportaba para el cura. Si bien su testimonio se esforzó en remarcar la "colaboración" que desde siempre había prestado a las autoridades locales -lo cual había quedado evidenciado en las "celebraciones religiosas y políticas" que compartieron, como así también en la recepción de

21 Carta de Ángel Diez y Menéndez a Juan Carlos Aramburu. 11 de septiembre de 1952. Legajo de Diez y Menéndez. AAT, San Miguel de Tucumán.

22 Cabe señalar que la acusación católica con respecto a la inmoralidad de los espectáculos tenía largos antecedentes en el catolicismo de la primera mitad del siglo XX. En ese sentido, puede tenerse como ejemplo la presión de la Acción Católica en los años treinta para popularizar la "calificación moral" de espectáculos y la difusión de grillas con películas aceptables o no.

23 Carta de José P. Albornoz a Juan Carlos Aramburu. 29 de agosto de 1952. Legajo de Diez y Menéndez. AAT, San Miguel de Tucumán. 
funcionarios en la casa parroquial-, ${ }^{24}$ quedó clara la desaprobación del sacerdote a los cambios introducidos ante la emergencia de los obreros y las mujeres como factores de poder local.

Precisamente, la sumatoria de las tensiones descriptas terminó por hacer eclosión la noche del deceso de Eva Perón, cuando Diez y Menéndez se enfrentó a la población como consecuencia de su negativa a habilitar la iglesia para que los fieles rezaran. El momento elegido por los vecinos para denunciarlo no fue fortuito. La coyuntura representada por la muerte de Eva Perón abrió paso a un clima de intensa polarización, que contribuyó al florecimiento de ese tipo de expresiones y mostró al gobierno receptivo de esos gestos, entendidos como muestras de lealtad política. ${ }^{25}$ En ese sentido, Leoncio Acosta expresó que como "argentino y peronista, defensor celoso de las instituciones de la Patria", se veía obligado a denunciar al cura por su antiperonismo y su supuesto pasado "comunista". ${ }^{26}$ Tales expresiones remiten a una práctica de la denuncia como una suerte de acto cívico a partir del cual el denunciante mostraba su lealtad al gobierno y a la Patria. ${ }^{27}$ El pedido de traslado del párroco de Famaillá no solo fue elevado al Ministro del Interior, también se plasmó en una presentación ante el obispo de la diócesis. ${ }^{28}$ No obstante, cabe señalar que, en ese caso, los términos y las causas a las que apelaron los vecinos fueron divergentes. Los suscriptos legitimaron su demanda en su carácter de "católicos", "asiduos concurrentes a la parroquia local" y "respetuosos de la investidura eclesiástica". Sin referirse a la adscripción política de Diez y Menéndez, en la solicitud apelaron a conceptos que referían a un buen ministerio pastoral, tales como la importancia de "hacer reinar la paz, la armonía y la unidad" entre los fieles. En

24 Carta de Ángel Diez y Menéndez a Juan Carlos Aramburu. 11 de septiembre de 1952. Legajo de Diez y Menéndez. AAT, San Miguel de Tucumán.

25 Flavia Fiorucci estudió la denuncia en el campo educativo bajo el período peronista. Si bien se trató de un ámbito distinto al aquí analizado, retomamos de su investigación el abordaje de la denuncia como un fenómeno que funcionó muchas veces como una vía de transmisión de tensiones de orden diverso, entre las que no estuvieron ausentes los problemas personales: "La denuncia de antiperonismo es instrumental a una guerra entre vecinos. Es en este sentido que la misma deja entrever los quiebres que la emergencia del peronismo produjo en el orden local, incluso cuando no todas las acusaciones respondían en forma inmediata a motivaciones políticas" (Fiorucci, 2013: 10). Agradezco a la autora el envío del texto citado.

26 L. Acosta también era miembro de la Sociedad Obrera San José y fue, junto con Isa, uno de los principales impulsores de las denuncias. Carta de Rubén Leoncio Acosta al Ministro del Interior Ángel Borlenghi, incluida en el Memorándum. Julio de 1952. Correspondencia Oficial con el Ministerio de Relaciones Exteriores y Culto. AAT, San Miguel de Tucumán.

27 Fiorucci (2013,p. 15) relaciona la práctica de la denuncia con cierta noción de ciudadanía que el peronismo promovió, sostiene que: "Es el arma de quienes asumen activamente la tarea de vigilar y proteger la palabra peronista que no es más que, en la nueva retórica, la patria misma".

28 Carta de Juan Isa y Leoncio Acosta a Juan Carlos Aramburu. 14 de agosto de 1952. Legajo de Diez y Menéndez. AAT, San Miguel de Tucumán. 
efecto, sindicaron al cura cualidades inadmisibles para un representante de la Iglesia, tales como el "maltrato", el "interés y apego al dinero" y el ánimo de generar "divisionismos" entre los católicos del pueblo.

Finalmente, el obispo auxiliar de la diócesis replicó el planteo del gobierno a través de un informe en el que explicó detalladamente la situación de persecución que sufría el párroco a cargo de un sector anticlerical y comunista. Tal informe reprodujo al pie de la letra la versión de Diez y Menéndez y refutó las acusaciones de "desafecto al gobierno", a tono con los argumentos vertidos por el cura en su alegato. ${ }^{29}$ Juan Carlos Aramburu -quien había quedado a cargo de la diócesis desde el fallecimiento del obispo Agustín Barrere a principios de 1952- decidió mantenerlo en su puesto, con lo cual reafirmó el poder de decisión que le cabía en esos casos y delimitó la esfera de competencia de la Iglesia frente al Estado. Desde el gobierno recibieron el informe del obispo y no volvieron a insistir en el traslado del cura.

De ese modo, Diez y Menéndez pudo seguir ejerciendo sus funciones en Famaillá gracias al apoyo del obispo. No obstante, los acontecimientos posteriores y los términos en los que renunció a sus funciones confirmaron el malestar que generaba su presencia entre la población local. En el contexto del conflictivo año 1955, su continuidad como párroco se tornó insostenible y presentó la renuncia aduciendo el retorno a su tierra natal. En una carta privada al obispo, admitió que quería "dejar el camino libre" para que se nombrase una persona "más grata para la Curia y la feligresía", y reconoció finalmente el "fracaso" de su paso como sacerdote en el pueblo. ${ }^{30}$ Los términos de la renuncia dieron cuenta de que el cura había desempeñado sus funciones en conflicto con su grey, pero también que su perfil no resultó del todo aceptable para la jerarquía tucumana. Por un lado, para la población parroquial, sus conductas se desviaban de lo que representaba un buen párroco. Por otro lado, la curia no podía estar conforme con un cura que sostenía un enfrentamiento con los fieles.

\section{El cura párroco de Monteros: entre la adhesión al peronismo y la obediencia a la jerarquía}

Nacido en 1910 en Belén, un pueblo de la provincia de Catamarca, Simón Pedro Lobo llegó a Tucumán a los veintidós años de edad para hacerse

29 Carta de Juan Carlos Aramburu a Benítez de Aldama. 2 de octubre de 1952. Correspondencia con el Ministerio de Relaciones Exteriores y Culto. AAT, San Miguel de Tucumán.

30 Carta de Ángel Diez y Menéndez a Juan Carlos Aramburu. 23 de octubre de 1955. Legajo de Diez y Menéndez. AAT, San Miguel de Tucumán. 
cargo de la parroquia Nuestra Señora del Rosario de Monteros, en carácter de vicario ecónomo. ${ }^{31}$ En contraste con Diez y Menéndez, el presbítero Lobo se mostró afín al movimiento comandado por el presidente Juan Domingo Perón desde su emergencia en la escena pública. Al igual que la mayoría de los sacerdotes de la diócesis, participó activamente en los actos paradigmáticos de la liturgia peronista, tales como los festejos por el Día de los Trabajadores $\left(1^{\circ}\right.$ de Mayo) y de la Lealtad (17 de Octubre). Junto con otros curas, dictó periódicamente conferencias en las bibliotecas obreras de los ingenios y acompañó al intendente y su comitiva en los actos de gobierno. ${ }^{32}$ En líneas generales, la jerarquía eclesiástica toleró ese tipo de conductas aunque no dejó de remarcar su arista "política". Se trataba de una faceta que el obispo buscó desalentar entre los religiosos, cuyo carácter de pastores de su comunidad no se condecía con la toma abierta de postura respecto a un partido determinado.

Estos dilemas se agudizaron durante los años peronistas, contexto en el cual los curas ampliaron su participación en la vida política de las poblaciones locales. La interacción con los sindicatos obreros azucareros -actores que emergieron en la escena política local en consonancia con el ascenso del peronismo- coadyuvó a que las funciones de los sacerdotes adquirieran mayor densidad e intensidad en comunidades con un mayor nivel de politización. Si se observa la dinámica de las relaciones entre el cura y el sindicato en Monteros, emerge con claridad la visibilidad que alcanzó la actividad política de los párrocos. En 1946, con motivo del $1^{\circ}$ de Mayo, el sindicato de trabajadores del ingenio Ñuñorco organizó una concentración en la plaza de la localidad en la que Lobo ofició de orador destacando "el significado del día del trabajo". ${ }^{33}$ Ese mismo año, en los actos por el 17 de Octubre, a "pedido de la concurrencia", Lobo improvisó un discurso en el que "ensalzó las figuras de Perón y Eva", seguido por el comisionado local y el secretario general del sindicato obrero que convocaba al acto. ${ }^{34}$ Como lo demuestran estos ejemplos, los gremios fueron un factor activo de poder en las celebraciones y en la politización de las comunidades locales. Las organizaciones obreras que auspiciaron las celebraciones

\footnotetext{
31 La parroquia, una de las más antiguas de la diócesis, se encontraba en el municipio de Monteros, ubicado a $53 \mathrm{~km}$ de distancia de la capital de la provincia. La ciudad pertenecía al departamento de Monteros, que se caracterizaba, al igual que Famaillá, por su actividad azucarera (tenía seis ingenios) y por la importante presencia del sector cañero, que redundaba en una acentuación del tamaño medio de las explotaciones. En las elecciones de 1946, el Partido Laborista triunfó con el $57,1 \%$ de los votos.
}

32 Sobre las conferencias para obreros que dictó en la Biblioteca Obrera de Santa Lucía, junto con un grupo de sacerdotes afines al peronismo, remitirse a La Gaceta del 9 de noviembre de 1948, p. 9. Archivo del diario, San Miguel de Tucumán.

33 La Gaceta, 3 de mayo de 1946, p. 4. Archivo del diario, San Miguel de Tucumán.

34 La Gaceta, 18 de octubre de 1946, p. 5. Archivo del diario, San Miguel de Tucumán. 
peronistas otorgaron a los párrocos un rol importante, al oscilar su función entre el oficio de misas y la ocupación de un lugar principal entre los oradores.

El hecho de consolidar su rol en la dinámica de la vida política de la población donde ejercía su ministerio pastoral, llevó a Lobo a recoger y, en algunos casos, a canalizar hacia los poderes estatales las demandas locales en materia de obras edilicias. Los pobladores de Monteros aún lo recuerdan como un cura "muy peronista" que tenía una relación fluida con los altos mandos de gobierno, lo cual le permitió gestionar varias obras, entre las que se destacó la construcción de un edificio nuevo para la escuela de la villa en la que ejercía la docencia. ${ }^{35}$

Como veremos, al igual que en Famaillá, la muerte de Eva Perón recreó en Monteros un escenario conflictivo que involucró al párroco. Ambas trayectorias tuvieron, no obstante, un desenlace divergente, ya que el enfrentamiento de Lobo con el obispo auxiliar Juan Carlos Aramburu lo llevó a perder las licencias ministeriales y a ser expulsado de la diócesis, máxima sanción eclesiástica de la que podía ser objeto un sacerdote.

Distintas razones pesaron en la drástica decisión tomada por Aramburu, cuyos fundamentos fueron expuestos en un extenso informe remitido al obispado de Catamarca, diócesis de la que dependía Lobo. ${ }^{36}$ Desde la perspectiva del obispo, el cura se había "extralimitado de sus funciones", dado que su "comportamiento político" había trastocado la "armonía de las relaciones con sus feligreses" que todo sacerdote estaba obligado a sostener. La "inconducta" se había plasmado en una "doble tendencia en su predicación": usaba el púlpito para agraviar a determinados feligreses, lo que motivaba la reiterada denuncia de estos últimos, e insistía demasiado en temas de carácter "netamente políticos". Al parecer, los "agravios" se centraban en la denuncia de los "antiperonistas" del pueblo y de la "oligarquía contrera", representada por los directivos del ingenio azucarero Santa Lucía, blanco de los "ataques" del párroco. Otras razones que llevaron a la jerarquía eclesiástica a atribuir un incumplimiento de sus deberes fueron que publicaba artículos de opinión política en una revista local, sin la debida autorización de la institución religiosa, y que, desde su rol de docente de religión en la escuela Normal, difundía el Segundo Plan Quinquenal. ${ }^{37}$

\footnotetext{
35 Entrevista a Tulio Santiago Ottonello realizada el 17 de diciembre de 2007. Nacido en Monteros, Ottonello es hijo de un militante importante de Acción Católica de esa localidad y conoció de cerca al cura Lobo.

36 Carta de Juan Carlos Aramburu al obispo de Catamarca, Carlos Hanlon. 10 de julio de 1953. Legajo de Simón Pedro Lobo. AAT, San Miguel de Tucumán.

37 Carta de Lobo al Vicario General. 5 de junio de 1953. Legajo de Simón Pedro Lobo. AAT, San Miguel de Tucumán. Lobo señaló que enseñaba el Plan Quinquenal "como está dispuesto por el gobierno y tiene que ser".
} 
En un primer momento, tales episodios le valieron al cura reiteradas advertencias por parte del obispo, quien alimentaba sus sospechas de que éste padeciera una "enfermedad mental", versión que circulaba también entre vecinos de Monteros. Con el fin de conocer el caso con mayor profundidad, a principios de 1952, Aramburu encomendó a Ramiro Pego Fuentes, vicario general de la diócesis, que "con suma reserva" Ilevara a cabo una investigación en el pueblo. Ésta arrojó como resultado que Lobo no mostraba "ningún signo manifiesto de alteración mental", razón por la cual desde el obispado le recomendaron que "se limitara a predicar la doctrina del evangelio". ${ }^{38}$

Sin embargo, las diferencias se profundizaron y dieron un giro inexorable en julio de ese año cuando, tras la muerte de Eva Perón, el párroco exteriorizó de forma más contundente su adhesión al peronismo, lo que derivó en expresiones y actitudes que generaron nuevas polémicas y culminaron en su destitución. El detonante fue un incidente con la directora de la escuela Normal, quien denunció que en una misa por el sufragio del alma de Eva Perón, a la que habían asistido alumnos, dirigentes sindicales y autoridades locales, Lobo la "agravió gratuitamente" y criticó a todo el personal del establecimiento. ${ }^{39}$ Los reproches tenían su origen en una presentación, no avalada por la directora, en la cual el sacerdote solicitó al Ministerio de Educación de la Nación el cambio de nombre de la escuela "Gral. Julio A. Roca" por el de la esposa del presidente. Desde el púlpito, el sacerdote acusó al personal docente con las siguientes palabras:

\footnotetext{
"He esperado muchos días para ver si los ingratos de la Escuela Normal pedían el cambio del nombre de la escuela por el de Eva Perón. Esa escuela tiene focos infecciosos. No se enseña la Doctrina Justicialista de Perón. Las maestras que pidieron algo a Evita y luego la traicionaron no son maestras. La directora y maestros que así proceden son unos hipócritas...Son unos ingratos, antes andaban entre ratones y murciélagos y hoy tienen edificio nuevo gracias a la Sra. de Perón". ${ }^{40}$
}

\footnotetext{
38 Episodio citado en el informe remitido por Juan Carlos Aramburu a Carlos Hanlon. 10 de julio de 1953. Legajo de Simón Pedro Lobo. AAT, San Miguel de Tucumán.

39 Carta de la directora de la Escuela Normal, María Inés Díaz de Osorio, a Lobo. 11 de septiembre de 1952. Legajo de Simón Pedro Lobo. AAT, San Miguel de Tucumán.

40 Dichos reproducidos en la carta de la directora enviada a Lobo. 11 de septiembre de 1952. Legajo de Simón Pedro Lobo. AAT, San Miguel de Tucumán.
} 
No conforme con estas acusaciones públicas, el párroco denunció a la directora en la policía local, lo que motivó un allanamiento a la escuela por parte de la fuerza pública. En efecto, hacia fines de 1952, las críticas de Lobo a los opositores al gobierno trascendieron el ámbito de la iglesia y se plasmaron en denuncias a la policía y a las autoridades políticas locales y nacionales, que generaron nuevos allanamientos en la escuela y en el ingenio Santa Lucía. ${ }^{41}$

En este punto cabe detenerse a considerar los elementos que tuvo en cuenta la jerarquía tucumana para definir el destino de Lobo. Ciertamente, el hecho de que un sacerdote tuviera expresiones de adhesión al peronismo y acompañara a la población en las celebraciones políticas identificadas con ese movimiento no era algo ajeno a la dinámica parroquial durante esos años. Aunque, en muchos casos, la jerarquía atribuyó a esas conductas un tinte "político", ésta no las reprendió, y se limitó a señalar algunas advertencias sobre la prudencia y la mesura que debían caracterizar al ministerio parroquial. El caso del cura de Monteros evidenció, no obstante, los límites de esa tolerancia. En efecto, las "extralimitaciones" del sacerdote no solo se cifraron en la exteriorización desmedida de su posicionamiento político sino, principalmente, en su desconocimiento de las pautas de comportamiento que atravesaban implícitamente la labor religiosa. En ese sentido, aunque los párrocos no se atuvieron del todo a las normas explicitadas por el Sínodo Diocesano de 1931, gravitaba en su proceder un consenso tácito en torno al lenguaje que utilizaban y a las demarcaciones que envolvían sus conductas. ${ }^{42}$ Ese límite fue cruzado por Lobo desde el momento en que emprendió la denuncia policial de quienes -según el cura- eran opositores al gobierno y acusó personalmente a pobladores desde el púlpito, impartiendo insultos y encabezando los pedidos de denominación de instituciones y calles con el nombre de Eva Perón.

En el contexto recreado tras la muerte de la Primera Dama, la actuación de Lobo expresó un cierto aire de familia con el que adoptaban las autoridades políticas y la población en general a la hora de mostrar fidelidad al gobierno, y se alejaba, por lo tanto, de las expectativas de la jerarquía. Tales muestras de adhesión exteriorizaban la lealtad a las figuras de Perón y Eva a través de la edificación de bustos en su homenaje, propuestas de cambio de nombre de establecimientos educativos o calles por los de los líderes políticos, como también la denuncia entre pares, amparada bajo la noción de "desafecto" al superior gobierno. En un marco en el que esas muestras de adhesión se

41 Carta de Juan Carlos Aramburu a Carlos Hanlon. 10 de julio de 1953. Legajo de Simón Pedro Lobo. AAT, San Miguel de Tucumán. En su investigación, Pego Fuentes también advirtió que Lobo hacía "muchas denuncias a la policía".

42 Sobre las conductas que debían seguir los párrocos frente a las autoridades políticas y las leyes civiles, véase obispado de Tucumán (1931, pp. 23-53, 66-67). 
generalizaron entre la población, el párroco asumió el comportamiento de un vecino peronista más. Lejos de diferenciar su figura del resto de los fieles, el rol que desempeñó y sus formas de intervención social lo involucraron de lleno en las disputas cotidianas. De ese modo, desde la perspectiva obispal, Lobo se inmiscuyó demasiado en los problemas mundanos, en lugar de aplacar las tensiones o descomprimir las disputas políticas.

Aunque estas razones pesaron, indudablemente, en la sanción impartida a Lobo, existieron otros motivos que inclinaron la balanza en su contra. Según el informe que fundamentó su expulsión de la parroquia, éste sufría una enfermedad mental "por todos conocida". Ciertamente, se trataba de una posición compartida por algunos vecinos del pueblo. ${ }^{43}$ Sin embargo, el argumento del "desequilibrio mental" fue el único que destacó Aramburu en la solicitud dirigida a Benítez de Aldama (director de Enseñanza Religiosa) con el objeto de obtener la baja de las horas de docencia que el sacerdote tenía en la escuela local. ${ }^{44}$ Probablemente, tal argumento haya sido subrayado por la máxima autoridad diocesana con el fin de evitar una posible intervención del gobierno.

El desenlace de esta historia afectó la carrera de Simón Pedro Lobo, quien debió aceptar la pérdida de sus licencias ministeriales y retirarse de Monteros abandonando la parroquia, no sin antes difundir un volante en el que narraba su actuación al frente del templo local y se defendía de las acusaciones de la jerarquía eclesiástica. El derrotero posterior del cura fue aún más sinuoso. Según un informe publicado por el diario Democracia en febrero de 1955, luego de regresar a Catamarca fue internado en un manicomio por demencia, a instancias de un certificado expedido por el médico de la curia de esa provincia. ${ }^{45} \mathrm{Al}$ poco tiempo, fue liberado gracias a las gestiones de un inspector de sanidad que "corrigió el abuso" y dispuso su salida del hospicio. Sin embargo, el "infortunado sacerdote" fue nuevamente detenido por dos empleados del manicomio y trasladado a una clínica en Córdoba. Hacia 1955, en pleno conflicto entre el gobierno peronista y la Iglesia católica, Lobo obtuvo la ayuda del "defensor de menores, pobres y ausentes", quien tramitó un dictamen por el cual se dio cuenta de que no padecía ninguna enfermedad mental, tras lo cual

\footnotetext{
43 Carta de Juan Carlos Aramburu a Carlos Hanlon. 10 de julio de 1953. Legajo de Simón Pedro Lobo. AAT, San Miguel de Tucumán. Según Ottonello, en los últimos años Lobo dio muestras de cierto "desequilibrio mental”. Entrevista realizada por la autora el 17 de diciembre de 2007.

44 Carta de Aramburu al director de Enseñanza Religiosa, Benítez de Aldama. $1^{\circ}$ de julio de 1953. Legajo de Simón Pedro Lobo. AAT, San Miguel de Tucumán.

45 Reintégrase a su actividad un sacerdote al que acosaba la curia local (1955, febrero 25). Democracia, nota consultada en Actualidad argentina: el clericalismo y las organizaciones del pueblo. Intentona revolucionaria. 1954-1955. Tucumán, libro de recortes periodísticos locales y nacionales localizado en el Archivo de la Legislatura de Tucumán, San Miguel de Tucumán.
} 
el interventor del poder judicial en esa provincia dispuso la inmediata libertad del interesado. La nota finalizaba con una declaración del cura, quien atribuyó la persecución a las "disidencias políticas mantenidas con algunas autoridades eclesiásticas" ${ }^{46}$

\section{Consideraciones finales}

El objetivo del artículo fue analizar las tensiones que atravesaron las trayectorias de dos párrocos de la diócesis de Tucumán durante los años peronistas. Los presbíteros Ángel Diez y Menéndez (Famaillá) y Simón Pedro Lobo (Monteros) vivenciaron episodios conflictivos que tuvieron como telón de fondo la muerte de Eva Perón, coyunturas que derivaron en enfrentamientos que envolvieron al obispo, al gobierno y a la población local. A partir de la lente que nos ofrecieron los legajos personales de ambos sacerdotes, en los que se cruzan las voces de los distintos actores involucrados, procuramos dar cuenta de las implicancias que tuvo el surgimiento del peronismo en el rol de los curas y el modo en que la antinomia con el antiperonismo repercutió en su ministerio pastoral. La riqueza de estos documentos nos permitió acceder a una dimensión analítica circunscripta al ámbito parroquial, perspectiva desde la cual la relación de la Iglesia y el peronismo permanece casi inexplorada.

La emergencia del peronismo introdujo importantes cambios en el tablero de poder de las poblaciones azucareras tucumanas y propició la aparición de nuevos actores políticos y sociales, lo cual impactó en la dinámica de las comunidades. En ese escenario, los vínculos entre los curas y las poblaciones locales se complejizaron. Los párrocos ampliaron su participación en las celebraciones políticas, comportamiento que agudizó las tensiones con la jerarquía eclesiástica. En efecto, la intensa politización que caracterizó a los pueblos azucareros de la provincia también repercutió en las expectativas en torno a la participación política de los religiosos, de quienes se esperaban muestras de acompañamiento y apoyo a la causa peronista. No obstante, la contracara de esta receptividad a las demandas de la población fueron las tensiones generadas con el obispo diocesano, quien procuró contener las expresiones de los curas a favor del movimiento comandado por Perón.

El problema no se circunscribió a la inclinación política de los sacerdotes, que el obispo toleró hasta cierto punto. Ese comportamiento se contraponía

46 El recuerdo de Tulio Ottonello coincide con este desenlace, aunque el entrevistado aseveró que Lobo falleció al poco tiempo en el hospicio de Oliva. Ottonello, junto con un grupo de vecinos de Monteros, viajó a Córdoba para rescatar los restos de Lobo cuando se enteraron que el obispado de Catamarca ya había gestionado el traslado a esa provincia para sepultarlo en "el panteón con los demás curas". Entrevista realizada por la autora el 17 de diciembre de 2007. 
al modelo de cura que el prelado Agustín Barrere había intentado implementar desde su asunción al frente de la diócesis en 1930. Es decir, un perfil de sacerdocio alineado a las directivas obispales, cuyo ministerio pastoral se desarroIlase principalmente bajo la órbita de la autoridad jerárquica. Sin embargo, las transformaciones que introdujo el peronismo coadyuvaron a forjar un perfil de párroco más abocado a resolver los problemas locales y a construir vínculos con actores comunitarios, lo cual amplió las tensiones con la jerarquía eclesiástica. Las fricciones propias del rol bifronte de los curas se vieron exacerbadas, y éstos debieron pivotear entre su dependencia de la esfera local -como representantes de la comunidad de fieles- y la observancia de la autoridad eclesiástica. En ese sentido, las tensiones generadas encontraron en la trayectoria del párroco de Monteros su máxima expresión.

El caso de Lobo puso en jaque el proyecto de Barrere. Ciertamente, el desafío implícito en el comportamiento del religioso no solo expuso políticamente a la institución eclesiástica sino que llevó al extremo las tensiones entre dos modelos contrapuestos de sacerdocio. Su ministerio pastoral estuvo cruzado por una colaboración estrecha con las autoridades políticas locales, por la adhesión a los reclamos obreros en contra de los sectores patronales y por su participación protagónica en los actos peronistas. Asimismo, frente a la muerte de Eva Perón dio muestras ejemplares de lealtad al gobierno. De ese modo, en lo que Lobo sí se diferenció del clero en general -que también había exteriorizado su adhesión al gobierno- fue en su ruptura con la jerarquía eclesiástica a partir de un comportamiento que desconoció las demarcaciones implícitas a la labor de los curas. Para la jerarquía, resultaba inaceptable que un párroco aspirara a construir un liderazgo local a partir de arengas políticas definidas a favor del peronismo y al rechazo de los opositores, tal como lo había hecho Lobo en su iglesia. De alguna manera, su historia reveló las restricciones impuestas por la jerarquía a la afirmación de las proyecciones políticas de los curas que consolidaban su poder local.

Por el contrario, el camino elegido por Ángel Diez y Menéndez lo llevó a ejercer su ministerio pastoral en conflicto constante con la grey católica. Su trayectoria expresó una crisis en los vínculos que lo ligaban a la comunidad. Como lo reveló su caso, la adhesión abrumadora de la población al nuevo movimiento político supuso un condicionamiento al desempeño de los sacerdotes, especialmente si se trataba de eclesiásticos que no comulgaban con la causa peronista. Su negativa a abrir las puertas del templo para homenajear a Eva Perón fue el detonante que llevó a que resentimientos previos en torno a su gestión, diferencias de clase y hasta problemas personales estallaran bajo la antinomia peronismo-antiperonismo. 
En suma, las trayectorias de ambos reflejan, desde registros diferentes, los quiebres que introdujo el peronismo en la relación entablada por los curas hacia arriba (con la jerarquía) y hacia abajo (con la comunidad). Pero también dan cuenta de las formas que adquirió la conflictividad en el ámbito parroquial bajo los años peronistas, de la resignificación de las tensiones que atravesaron los vínculos trazados entre los sacerdotes y las poblaciones locales, y de la redefinición de las pugnas constantes por los modelos de párrocos.

\section{Referencias bibliográficas}

1. Ayrolo, V. (Comp.) (2006). Estudios sobre clero iberoamericano, entre la independencia y el Estado-Nación. Salta: Centro Promocional de Investigaciones en Historia y Antropología, Facultad de Humanidades, Universidad Nacional de Salta.

2. Barral, M. E. (2007). De sotanas por la Pampa. Religión y sociedad en el Buenos Aires tardocolonial. Buenos Aires: Prometeo.

3. Bianchi, S. (2001). Catolicismo y peronismo. Religión y política en la argentina (1943-1955). Tandil: Instituto de Estudios Histórico-Sociales "Prof. Juan Carlos Grosso".

4. Caimari, L. (1995). Perón y la Iglesia católica. Religión, Estado y sociedad en la Argentina (1943-1955). Buenos Aires: Ariel.

5. Dirección Nacional del Servicio Estadístico. (1947). IV Censo General. Buenos Aires.

6. Di Stefano R. y Zanatta L. (2000). Historia de la Iglesia Argentina. Desde la conquista hasta fines del siglo XX. Buenos Aires: Grijalbo Mondadori.

7. Fiorucci, F. (2013). La denuncia bajo el peronismo. El caso del campo escolar. Latin American Research Review, 48 (1), 3-23. DOI:10.1353/ lar.2013.0004

8. Gutiérrez, F. (2012a). La dirigencia de FOTIA y los sindicatos de base: tensiones y conflictos en el proceso de sindicalización azucarera. Tucumán, 1944-1955. En F. Gutiérrez y G. Rubinstein (Coords.) El primer peronismo en Tucumán. Avances y nuevas perspectivas (pp. 133-164). Tucumán: Editorial de la Universidad Nacional de Tucumán.

9. Gutiérrez, F. (2012b). Desigualdad social, masculinidad y cualificación en el sindicalismo azucarero, Tucumán, 1944-1955. Ponencia presentada en las Jornadas "El asociacionismo en la Argentina del siglo XX". Ciudad Autónoma de Buenos Aires, 22 y 23 de noviembre, Instituto de Historia Argentina y Americana "Dr. Emilio Ravignani", Universidad de Buenos 
Aires/Consejo Nacional de Investigaciones Científicas y Técnicas.

10. Lichtmajer, L. (2013). Notas sobre la génesis del peronismo en el mundo azucarero tucumano. Prácticas y experiencias políticas en la escala local. Ponencia presentada en las XIV Jornadas Interescuelas/Departamentos de Historia. Mendoza, 2 al 5 de octubre, Facultad de Filosofía y Letras, Universidad Nacional de Cuyo.

11. Lida, M. y Mauro, D. (Coords.) (2009). Catolicismo y sociedad de masas en Argentina: 1900-1950. Rosario: Prohistoria.

12. Lida, M. y Mauro, D. (Eds.) (2011a). Catolicismo, Sociedad y Política: nuevos desafíos historiográficos. Polhis. Boletín Bibliográfico Electrónico, 8, 73-129.

13. Lida, M. y Mauro, D. (Coord.) (2011b). Catolicismo y política en la Argentina del siglo XX. Programa Buenos Aires de Historia Política. Disponible en: http://historiapolitica.com/dossiers/catolicismoypolitica/

14. Obispado de Tucumán (1931). Segundo Sínodo Diocesano de Tucumán. San Miguel de Tucumán: Escuela Tipográfica del Colegio Salesiano "Tulio García Fernández".

15. Rubinstein, G. (2006). Los sindicatos azucareros en los orígenes del peronismo Tucumano. Tucumán: Facultad de Ciencias Económicas, Universidad Nacional de Tucumán.

16. Santos Lepera, L. (2012a). La Iglesia católica y su relación con el gobierno peronista. Religión y política en Tucumán 1943-1955. En F. Gutiérrez y G. Rubinstein (Coords.) El primer peronismo en Tucumán. Avances y nuevas perspectivas (pp. 171-211). Tucumán: Editorial de la Universidad Nacional de Tucumán.

17. Santos Lepera, L. (2012b). Las parroquias de los pueblos azucareros de la diócesis de Tucumán durante los años treinta. En G. Caretta e I. Zacca (Comps.) Derroteros en la construcción de Religiosidades. Sujetos, instituciones y poder en Sudamérica, siglos XVII al XX (pp. 181-195). Salta: Centro Promocional de Investigaciones en Historia y Antropología, Facultad de Humanidades, Universidad Nacional de Salta-Universidad del Norte Santo Tomás de Aquino-Consejo Nacional de Investigaciones Científicas y Técnicas.

18. Touris, C. (2008). Entre la historia de la iglesia y los estudios sobre religión y sociedad en la Argentina contemporánea. En G. Caretta e I. Zacca (Comps.) Para una historia de la Iglesia. Itinerarios y estudios de caso (pp. 83-92). Salta: Centro Promocional de Investigaciones en Historia y Antropología, Facultad de Humanidades, Universidad Nacional de Salta-Universidad del Norte Santo Tomás de Aquino. 
19. Zanatta, L. (1996). Del Estado liberal a la nación católica. Iglesia y ejército en los orígenes del peronismo (1930-1943). Buenos Aires: Universidad Nacional de Quilmes.

20. Zanatta, L. (1999). Perón y el mito de la nación católica. Iglesia y ejército en los orígenes del peronismo (1943-1946). Buenos Aires: Sudamericana. 